Mariana Guerra Luz 


\section{¿Derecho natural o principio moral? Consideraciones en torno a los derechos de los animales}

\section{Introducción}

A lo largo de la historia de la humanidad, se ha creído que los seres humanos poseen cierta superioridad sobre el resto de los animales y de los recursos naturales en general, esto se debe en gran parte a las religiones que sostienen esta postura, otorgándoles a los seres humanos cierta proximidad divina, cuando en la Biblia se menciona que Dios hizo al hombre a imagen y semejanza suya, por ejemplo, y que dejó al resto de los animales en un plano inferior y a la disposición del ser humano para hacer cuanto se le antoje con ellos.

\section{Principio moral de los animales}

Así pues, la humanidad se ha dedicado a resaltar las características que los seres humanos poseemos a diferencia del resto de los animales y ha marcado una línea de diferenciación vertical, colocándonse, claro, sobre ellos. Vemos, pues, se les ha categorizado como seres que "[...] no hablan, caminan mal, no se saben sentar, el futuro les importa un bledo, no toman decisiones que debieran tomar, no escriben, no leen... en pocas palabras, los animales no sirven como humanos" ${ }^{1}$. El asunto animal nunca había sido abordado en la filosofía hasta hace apenas unas décadas, por lo que el especismo no se cuestionaba ni se vulneraba, puesto que se consideraba que no valía la pena cuestionarse sobre este tipo de asuntos o no se tenía la experiencia suficiente para discutir este problema.

1 Ramírez Barreto, Ana Cristina, De bumanos y otros animales, Ed. Dríada, México, 2009. 
De la misma manera, vemos cómo la consideración moral fue progresando y expandiéndose poco a poco, así podemos dividirla en tres etapas: en la primera, la consideración moral se aplicaba de manera exclusiva a los miembros de un mismo grupo, lo cual ocasionaba que hubiera racismo, sexismo, machismo, etcétera; en la segunda etapa, la consideración moral ya va dirigida a todos los miembros de una especie y la vemos manifestada, principalmente, en los principios de la revolución francesa (igualdad, fraternidad y libertad), mas esto no está del todo completo, puesto que nos lleva al especismo y a relegar al resto de las especies; así pues, por último está la tercera etapa, la cual da consideración moral a todo ser que tenga la capacidad de sentir, incluyendo así a todos los animales no humanos.

Ahora bien, desde la primera etapa se ha ido realizando una lucha por la justificación de los derechos humanos y nos encontramos con tres maneras distintas de fundamentar dichos derechos: el derecho natural, el derecho positivo y el derecho deontológico.

\section{Derecho natural de los animales}

El derecho natural, o iusnaturalismo, ha causado mucha controversia en debates políticos y filosóficos debido a su fundamentación, la cual tiene como objetivo dar cuenta de que existen derechos inalienables e universales que deben respetarse independientemente del contexto de la ley positiva. Así pues, "[... ] en cuanto al derecho natural, sabemos que es intrínseco, constitutivo y necesario, es decir, intrínseca y esencialmente bueno y justo; se refiere a los principios evidentes, supremos y universales" ${ }^{2}$, pero, claro, este derecho es exclusivo de la especie humana, pues se da, justamente, por la naturaleza de ésta como consecuencia lógica ${ }^{3}$. Según la corriente iusnaturalista, los seres humanos son los únicos capaces de poseer derechos puesto que al ser personas son, por tanto, dueños de su propio ser y del dominio de ellos mismos. En palabras de Jesús Gálvez:

2 Gálvez Yares, José Jesús, Ley natural y fundamentos del derecho, Junio, 2006, retomado de: http://www.filosofia.mx/index.php/portal/archivos/ley_ natural_y_fundamentos_del_derecho

3 Cfr. Idem. 
Dicho derecho natural se da en la naturaleza del ser humano, como consecuencia lógica de la misma; su conocimiento es común a los hombres desde el comienzo de la vida racional. El derecho natural es específicamente idéntico en todos los hombres de todos los tiempos y lugares [...], es un derecho cognoscible con facilidad y certeza, está contenido en las costumbres de todos los pueblos aún antes de las leyes escritas; es inmutable en cuanto a su esencia $[\ldots]{ }^{4}$

Por otra parte, los animales no pueden poseer derechos puesto que no se poseen a sí mismos. Sin embargo, nos encontramos con que esta corriente cae en un anacronismo, puesto que sostener esta postura jurídica muestra una concepción abstracta de los derechos naturales, debido a que ignora los hechos históricos, así como los de la realidad social y la conformación de dichos derechos. ${ }^{5}$

Así mismo, vemos que:

Dada la plasticidad de las doctrinas iusnaturalistas, no es de extrañar que históricamente esta ideología se haya empleado para justificar los más variados regímenes, desde las monarquías absolutas y las distintas dictaduras totalitarias, hasta las revoluciones liberales del siglo XVIII que culminaron con las primeras listas de derechos humanos que conoció la modernidad. Desde la esclavitud y la desigualdad entre los hombres, hasta la igualdad y la libertad. ${ }^{6}$

La idea del derecho natural ha hecho creer a la humanidad que los animales no son acreedores de derechos como los poseemos nosotros como especie humana, sin embargo, vemos que el derecho natural está ridículamente fundamentado, ya que "las diversas concepciones del derecho natural no se ponen de acuerdo [... en la fuente de tales principios universales e inmodificables [... ], ni en cuales son éstos"7, así como el hecho de que no haya un método específico para descubrir dichos principios, puesto que algunos sos-

\footnotetext{
4 Idem.

5 Vid. González Piña, Alejandro. Los derechos bumanos en perspectiva.

6 Ibidem p. 57.

7 Ibidem p. 56.
} 
tienen que es por revelación divina, otros por el uso de la razón, o bien por intuición. "Los derechos naturales, independientes de nuestras convenciones, no existen, son meras ficciones."

Dentro de la segunda etapa de la expansión de la consideración moral, como ya se ha ido mencionando, nos encontramos con un fuerte especismo a causa de la concepción naturalista de los derechos humanos, pero, pasando a la tercera etapa, nos encontramos con posturas que están en contra de dicho especismo y expanden la consideración moral al resto de los animales no humanos, debido a que "[... ] la capacidad de sufrir y de sentir dolor es central para determinar qué es un mal moral y qué no lo es, la mera pertenencia a una raza o especie [...] es irrelevante [... ${ }^{\prime \prime}{ }^{\prime}$

En cuanto a la línea que se ha intentado trazar entre animales y animales humanos, teniendo estos últimos una misma consideración moral entre sí, se han puesto en consideración las capacidades del lenguaje y del raciocinio, sin embargo, esta línea no puede ser trazada, ya que las capacidades de los humanos y los animales no humanos se solapan, debido a que hay animales con mayor capacidad de raciocinio que los bebés humanos y otras personas con discapacidad, a menos que se usen criterios especistas.

\section{Derechos de los animales}

Ahora bien, muchos sostienen que los animales no pueden ser poseedores de derechos puesto que éstos van ligados con obligaciones, y los animales no serían capaces de cumplirlas o no puede juzgárseles por sobrepasar los derechos de otros animales (un león que se come a un antílope, por ejemplo). Sin embargo, ésta es una idea totalmente errónea, puesto que derechos y obligaciones no van entrelazados de esa manera, sino que, como sostiene Kelsen, el hecho de crear un derecho para alguien implica la obligación o prohibición para alguien más, no para el sujeto de derecho. Es decir, los derechos de los niños a alimentarse y recibir una buena educación se convierten en obligaciones para sus padres y para el estado, sin

8 Mosterín, Jesús, "Los derechos de los animales", Baltasar, Basilio (coord.), El derecho de los animales, Ed. Cátedra de Estudios Iberoamericanos Jesús de Polanco, Madrid, 2015, p. 54.

9 Ibidem p. 52. 
que los niños tengan obligaciones causales. Así pues, "que alguien tenga ciertos derechos significa que los demás tienen determinadas obligaciones respecto a él (ella). Por eso los niños y los animales no humanos pueden tener derechos sin tener obligaciones." ${ }^{10}$

Por otra parte, Jesús Mosterín sostiene que existen tres tipos de derechos: derechos como capacidades legales, derechos como pretensiones y los inexistentes derechos naturales y el derecho o la legislación positiva, y afirma que este último es el único derecho que existe realmente, debido al carácter convencional de los derechos al ser creaciones humanas. "Los derechos no son algo que exista ya dado en la naturaleza y que nosotros nos limitemos a descubrir. Los derechos los creamos nosotros mediante nuestras convenciones legislativas. [... ] Así que la pregunta relevante no es ¿qué derechos tienen estos o aquellos?, sino ¿qué derechos queremos que tengan?"11

Ahora pues, si los derechos no tienen un fundamento natural y el fundamento positivo varía según cada contexto, ¿con base en qué principios se debe legislar a favor tanto de animales humanos como animales no humanos? La respuesta, creo yo, es clara: principios éticos universales.

"No podemos aplicar estándares distintos al sufrimiento de los animales humanos al de los no humanos. La moral es universal. Deberíamos considerar el sufrimiento ajeno tanto como el propio y el de los otros animales tanto como el de los congéneres." ${ }^{12}$

Llegamos, pues, a la tercera etapa de la consideración moral, dirigida a todo ser con sensibilidad o capacidad de sufrimiento, rechazando así el especismo, no por el hecho de dar importancia a la propia especie, sino por no dar importancia alguna al resto de las especies. ${ }^{13}$ Así pues, la lucha por la consideración moral a los animales no humanos ha logrado un paso importante con la implementación del Proyecto Gran Simio (PGS), que busca la protección de los grandes simios, así como de su hábitat natural de la misma forma en que se protegen los centros históricos de las ciudades que son patrimonio de la humanidad. Se trata, pues, de crear una comunidad de iguales, que no busca menospreciar la lucha por

\footnotetext{
10 Ibidem p. 54.

11 Ibidem p. 56.

12 Ibidem p. 53.

13 Cfr., Idem.
} 
la defensa de los derechos humanos ni dejarla de lado, sino simplemente expandir esta protección a nuestros parientes más cercanos. La Declaración del PGS sostiene que:

la 'comunidad de iguales' es una comunidad moral dentro de la cual aceptamos que determinados principios morales o derechos fundamentales, que se puedan hacer valer ante la ley, rijan nuestras relaciones mutuas. Entre estos principios o derechos figuran los siguientes:

- El derecho a la vida [...].

- La protección de la libertad individual [...].

- La prohibición de la tortura $[\ldots] .^{14}$

Así mismo, la declaración del PGS solicita a la ONU que acepte el reforzamiento de la condición moral a los simios antropoides, dentro de los cuales también se encuentra la especie humana.

Si nos permitimos pensar en derechos de otros animales que no cumplan con esta elemental condición de la especie, ¿̇acaso dejarán de ser convincentes las razones para la emancipación de los esclavos y las mujeres? Si la noción de dignidad y vida-quemerezca-vivirse se extiende más allá de la multifacética especie humana, ¿̇se revelará la inconsistencia de no discriminar y no restringir las esferas de oportunidades para una vida-en-florecimiento en función de diferencias supuestamente naturales, como el color de la piel o el sexo genital? ${ }^{15}$

El humanismo que se ha llevado a cabo a lo largo de la historia de la humanidad (el cual únicamente ha centrado sus temas de estudio antropológicos en la consideración moral humana) debe someterse a una crítica que permita ver las cosas desde otro punto de vista, como lo solicita el PGS. Es una tarea difícil de realizar, ya que constantemente nos encontramos con una dificultad de expandir nuestra compasión hacia el prójimo, en muchísimos aspectos, desde el vagabundo que nos encontramos en la calle, la gente que vive en pobreza extrema en los municipios cercanos, los pollitos

14 Ramírez Barreto, Ana Cristina, De bumanos y otros animales, p. 86.

15 Ibidem p. 87. 
que vemos encerrados en jaulas transportadas por un camión, hasta la gente que es bombardeada en Siria y los gorilas en peligro de extinción en África. Pero si no somos capaces de hacer conciencia sobre todo el mal que ha hecho la especie humana a lo largo de su existencia, no somos dignos de llamarnos humanos, en el pleno sentido de la palabra.

\section{Conclusión}

Dejemos de pensar que nuestra racionalidad nos da privilegios sobre el resto de las especies y del ecosistema en general, nuestra capacidad de razonar únicamente hace que debamos preocuparnos por las consecuencias de nuestras acciones, no poseer más derechos, sino que tenemos una obligación para con nuestro entorno en general (animales, recursos naturales, etcétera).

En palabras de Jesús Mosterín:

El combate por un mundo con menos destrucción, crueldad y sufrimiento también puede llevarse a cabo de un modo lúcido y filosóficamente satisfactorio, apelando sólo a cosas realmente existentes, como los animales, sus cerebros y sus emociones, incluida nuestra capacidad de sentir compasión por todas las criaturas capaces de sufrir. ${ }^{16}$

16 Op. Cit. Mosterín, Jesús, p. 65. 